\title{
Afghanistan politiopprustning for den avgjørende timen
}

\author{
Lemlestelse og $d ø d$ er en del av hverdagen til mange afghanere. Politiet er spesielt utsatt. De er ofte først \\ på skadestedet etter fiendtlige angrep og blir jevnlig også selv utsatt for voldshandlinger. Gjennom Forsvarets \\ politirådgivningsbidrag i Afghanistan, Norwegian Police Advisory Team (NOR PAT), utarbeidet jeg høsten 2013 \\ en modell for å styrke sanitetsberedskapen hos politiet i Mazar-e Sharif i Afghanistan.
}

\section{Jon Magnus Haga}

jon.magnus.haga@gmail.com

Norges militære engasjement i Afghanistan har tidligere vært mye diskutert, og jeg vil ikke her gå inn på bakgrunnen for det norske engasjementet. Jeg ønsker derimot å gi et eksempel på mulighetene Forsvaret gir for internasjonalt helsearbeid.

\section{Høy dødelighet i politiet}

Politihverdagen i Afghanistan har ofte en mer offensiv karakter enn det vi kjenner som politiarbeid i Norge. Politiet fungerer i stor grad som en paramilitær sikkerhetsstyrke, i tillegg til at de utfører mer tradisjonelt politiarbeid. I store og små militære operasjoner står politiet skulder ved skulder med hærens soldater mot opprørere og kriminelle nettverk.

Politiet i Afghanistan har det siste tiåret tatt betydelige tap gjennom kamphandlinger og terrorangrep. Mortaliteten hos en polititjenestemann i Afghanistan etter å ha blitt skadet i kamphandlinger (case fatality rate) er i dag høy og overgår tilsvarende tall for den afghanske hæren (36\% versus $22 \%$ ) (Afghan National Security Forces (ANSF) casuality data, januar-juli 2013, International Security Assistance Force (ISAF). Tall publisert med tillatelse fra kaptein Stephen Olsen, Forsvarets presseoffiser i Afghanistan høsten 2013). Tilsvarende tall for amerikanske soldater under den annen verdenskrig var til sammenlikning $30 \%$. I dagens konflikt i Afghanistan har andelen for koalisjonsstyrkene sunket til i underkant av $10 \%(1)$.

I Afghanistan er sanitet under politioperasjoner, evakuering og hospitalisering av sårede politiets eget ansvar. Oppgavene ivaretas hovedsakelig gjennom politiets egen helseinfrastruktur. I Mazar-e Sharif har politiet en egen politiklinikk, tilsvarende et stort fastlegekontor med ambulansetjeneste. I Kabul har politiet et eget syke- hus. Politiet har ikke eget sykehus i Mazar-e Sharif, men benytter dels hærens sykehus, dels det offentlige sykehuset $\mathrm{i}$ byen.

\section{Støtte til sanitetsutvikling}

Gjennom Anestesiprosjektet (2) bidro Norge i perioden 2006-12 til å utvikle anestesiavdelingen ved det offentlige sykehuset i Mazar-e Sharif. Til tross for den norske innsatsen innen anestesi har sykehuset i dag liten evne til å støtte politiet ved traumer, grunnet manglende kompetanse innen traumekirurgi (personlig meddelelse dr. Seddiqi, avdelingsoverlege i anestesiologi, Balkh offentlige sykehus).

ISAF har i flere år lagt stor vekt på å bygge ut saniteten i den afghanske hæren (personlig meddelelse dr. Fazekas, lege/ oberst i det ungarske forsvaret og sjef for sanitetsutvikling av de afghanske politi- og hærstyrkene i ISAF Nord). Hærens sykehus i Mazar-e Sharif har i dag et godt utbygd traumetilbud, også etter vestlig standard. Sykehuset er forpliktet til et «uniform blind environment», hvilket innebærer at hæren og politiet har rett til et likeverdig behandlingstilbud ved institusjonen.

\section{Til kamp uten sanitet}

Med bakgrunn i politiets direkte adgang til hærens avanserte traumekapasiteter betrakter jeg deres relative overdødelighet etter skade overveiende som et uttrykk for utfordringer ved politiets egen prehospitale praksis.

Den første tiden etter traume, «the golden hour», har avgjørende betydning for pasientoverlevelsen (3). I Afghanistan opererer politiet i et miljø der ytre sanitetsstøtte/-forsterkninger ikke kan påregnes. Prehospital sanitetsberedskap i politistyrken forutsetter derfor solid sanitetskompetanse og grunnleggende sanitetsutrustning hos samtlige tjenestemenn.

Politiutdanningen i Afghanistan omfatter åtte ukers grunnleggende ferdighetstrening (basic patrolman course) og inkluderer en halv dag med førstehjelpstrening (personlig meddelelse dr. Fazekas, lege/oberst i det

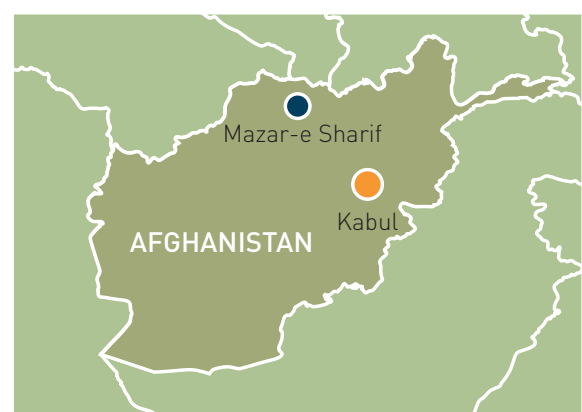

ungarske forsvaret og sjef for sanitetsutvikling av de afghanske politi- og hærstyrkene i ISAF Nord). Hver politimann skal dessuten, i henhold til afghanske retningslinjer, ha utstedt personlig sanitetsmateriell/førstehjelpsutstyr (turniké, trykkbandasje og nesekantarell). Den afghanske politistyrkens reelle førstehjelpskompetanse og reelle tilgang på sanitetsutstyr er imidlertid ikke blitt systematisk undersøkt.

Mine observasjoner av sanitetsundervisningen $\mathrm{i}$ «basic patrolman course» ga grunn til å tvile på i hvilken grad kurset var egnet til å gi politielevene nødvendig grunnleggende førstehjelpskompetanse. En betydelig andel av polititjenestemennene som jeg senere kom i kontakt med i Mazar-e Sharif, anga dessuten at de aldri hadde gjennomført noen form for førstehjelpsopplæring, til tross for at de hadde gjennomført nettopp «basic patrolman course», og ingen av dem jeg snakket med, sa de hadde tilgang til personlig førstehjelpsutstyr. Under ISAFs halvårlige militære samfunnsmedisinske konferanse i Kandahar høsten 2013 fikk jeg høre om tilsvarende erfaringer fra øvrige regioner av Afghanistan.

Afghansk politi opererer i et svært voldsutsatt miljø. Det er grunn til å tro at et stort antall polititjenestemenn daglig utsettes for voldsrisiko, uten at de har reell tilgang til grunnleggende sanitetsberedskap. En slik mangel på sanitet har både en uakseptabelt høy menneskelig kostnad og vil i tillegg bidra til å gjøre politistyrken mindre robust. 


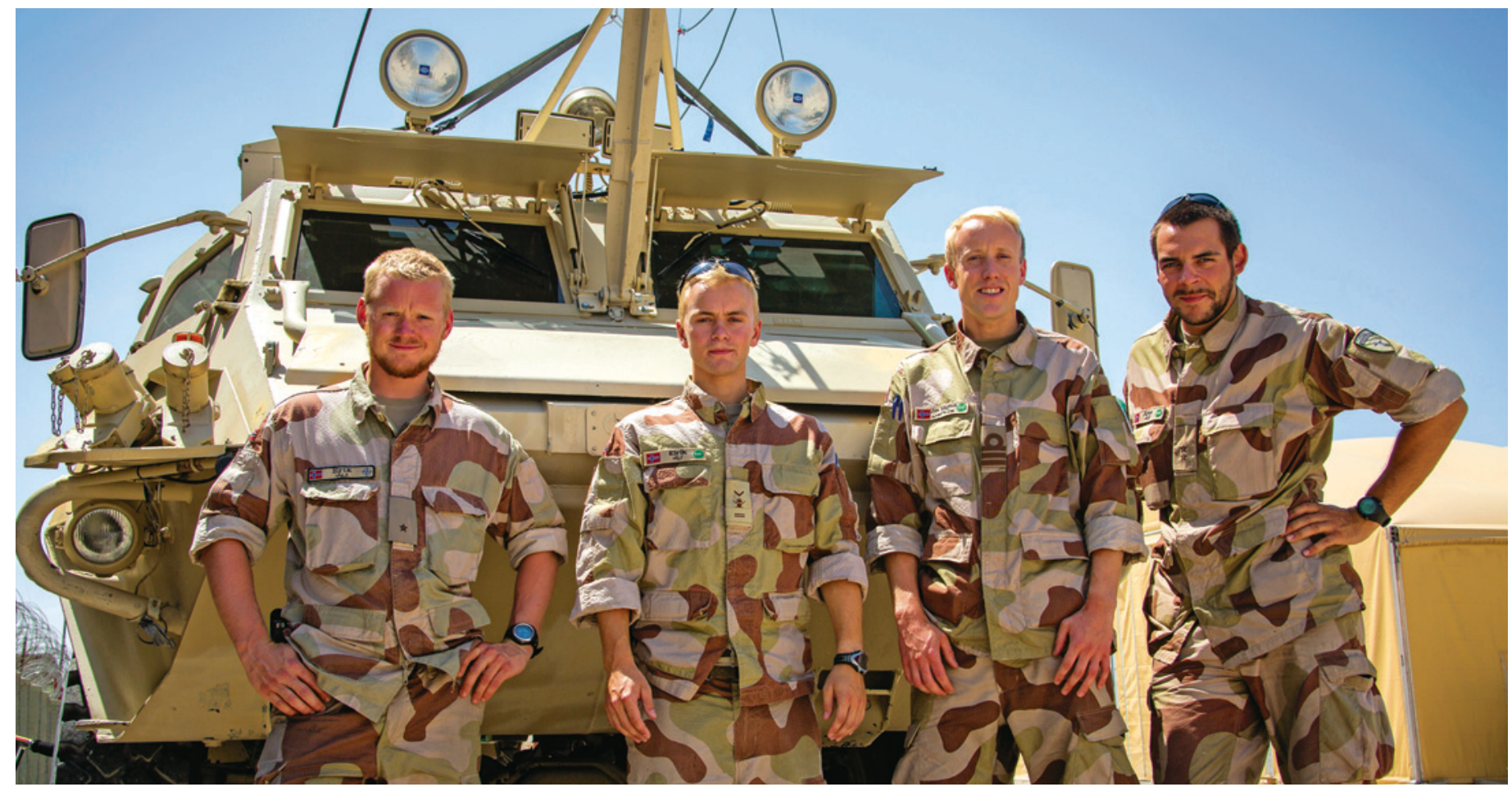

Medlemmene i politihelserådgivningsteamet. Fra venstre vognkommandør/fenrik Erik, vognfører/grenader Eirik, lege/orlogskaptein Jon Magnus og sykepleier/løytnant Arne. Foto: Forsvaret

\section{Helse for utvikling}

NOR PAT er Norges rådgivningsenhet for politiet i Afghanistan, underlagt ISAFkommando. Enhetens oppdrag er å bidra til bærekraftig utvikling av politiet i Mazar-e Sharif i Nord-Afghanistan. Tidligere har man i NOR PATs utviklingsstrategi ikke lagt særlig vekt på sanitet. Helse står etter min mening sentralt i utvikling av bærekraft. Som lege i NOR PAT så jeg derfor et betydelig potensial i en prehospital opprustning av saniteten i politistyrken i Mazar-e Sharif.

I tråd med NOR PATs overordnede råd- givningsoppdrag og $\mathrm{i}$ tett samarbeid med ISAFs medisinske kommando etablerte NOR PAT, under ledelse av oberstløytnant Halvor Johansen, høsten 2013 NordAfghanistans første politihelserådgivningsteam. Teamet besto av sykepleier/ løytnant Arne, vognkommandør/fenrik

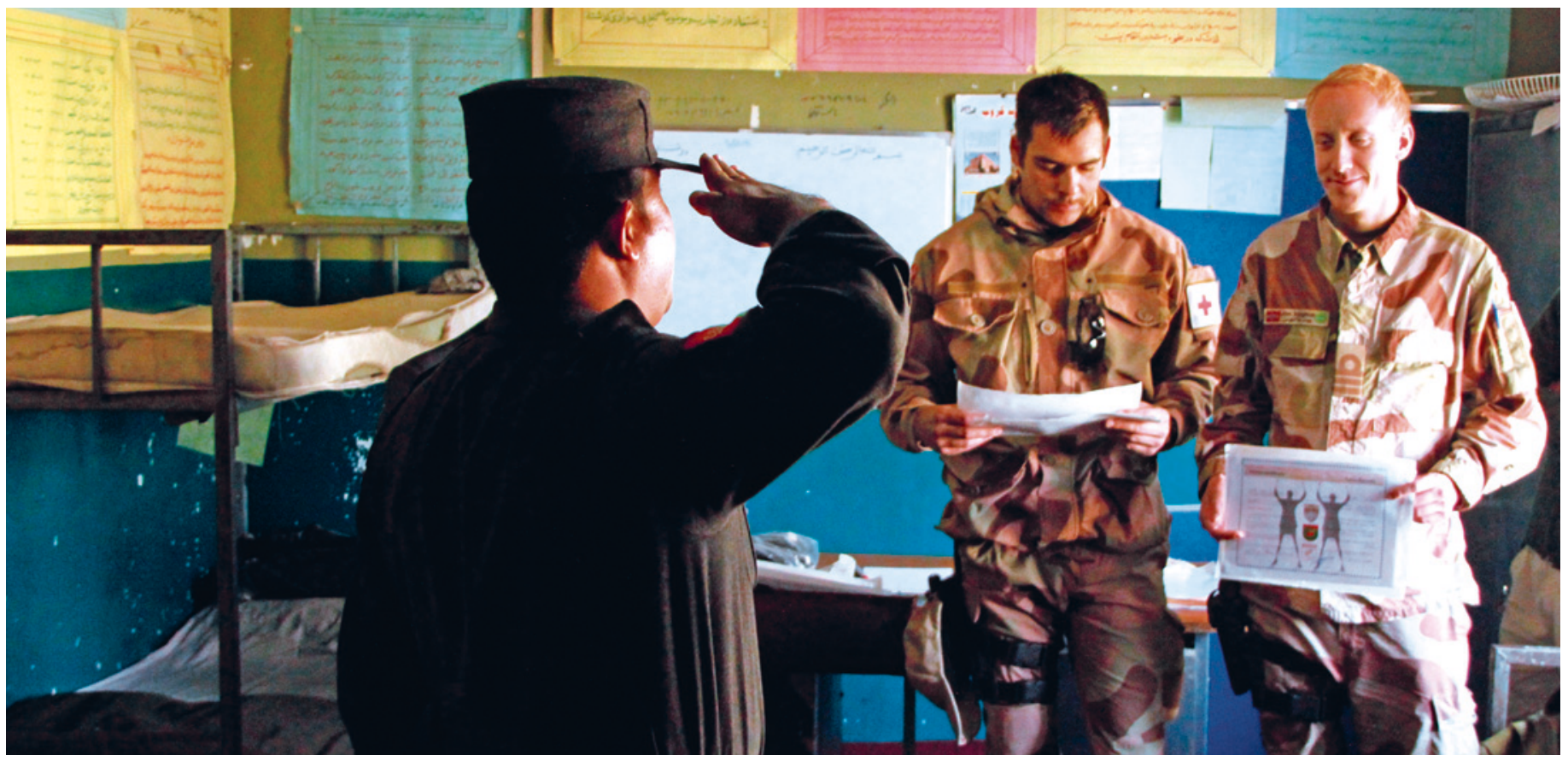


Erik og vognfører/grenader Eirik, i tillegg til undertegnede.

\section{Nøkkelen til bedret politihelse}

Vi var raskt i stand til å innhente detaljert informasjon om sanitetssituasjonen i samtlige politidistrikter i Mazar-e Sharif, med utgangspunkt i det nære samarbeidet mellom rådgiverlagene i NOR PAT og politisjefene i byen. Generalmajor Ehsas, sjef for politiet i provinsen Balkh, kontaktet oss dessuten tidlig med en invitasjon om å gjennomgå kapasitetene til politiklinikken i Mazar-e Sharif i detalj.

Resultatet av sanitetskartleggingen i politidistriktene var imidlertid nedslående. Vi var ikke i stand til å lokalisere én eneste politimann med spesielle oppgaver eller ansvar innen sanitet i noen av distriktene $\mathrm{i}$ byen, og det syntes å være lite oppdatert sanitetskompetanse å bygge videre på.

Politiklinikken i byen fremsto på den annen side stort sett faglig solid. Basert på den medisinske kompetansen blant helsepersonellet ved klinikken og tilgangen til medisinsk utstyr, forbruksmateriell og medisiner vurderte jeg at klinikken stort sett var i stand til å tilby forsvarlige grunnleggende allmenne helsetjenester til politiet i byen.

Nøkkelen til bedret politihelse lå derfor etter min mening i å utnytte ressursene og kompetansen tilknyttet politiklinikken i Mazar-e Sharif til å bygge opp sanitetsberedskapen ute i politidistriktene.

\section{Sanitetsopprustning \\ av politidistriktene}

I samarbeid med legene ved politiklinikken i Mazar-e Sharif etablerte vi et program for førstehjelpsutdanning av politiet i byen (4). Førstehjelpskursene ble gjennomført av legene fra politiklinikken ute på de lokale politistasjonene. Kursene omfattet to timers praktiske øvelser i bruk av turniké, trykkbandasje, nesekantarell og transport av syke og sårede. Målet var todelt - vi ønsket både å heve den generelle sanitetskompetansen i politidistriktene i Mazar-e Sharif og å knytte til oss personell med interesse for sanitetstrening. På den måten tok vi sikte på å legge til rette for fremtidige førstehjelpskurs i Mazar-e Sharif på halvårlig basis.

Kursdeltakerne ble forsynt med sanitetsmateriell i henhold til afghansk standard for personlig sanitetsutrustning (turniké, trykkbandasje og nesekantarell), forordnet gjennom det afghanske medisinske logistikksystemet av legene ved politiklinikken.

Samtlige kursdeltakere ble med utgangspunkt i et standardisert spørreskjema intervjuet av NOR PAT om tidligere førstehjelpserfaring, førstehjelpsutrustning og kjennskap til/erfaringer med politiklinikken i Mazar-e Sharif.

Det var en grunnleggende forutsetning i prosjektet at det skulle kunne videreføres også etter at Norge har forlatt Afghanistan. All aktivitet ble derfor organisert av afghanerne selv, det var afghanske undervisere og prosjektet var utelukkende finansiert av afghanske ressurser. NOR PAT støttet prosjektet gjennom hjelp til planlegging av kurset og rådgivning $\mathrm{i}$ forbindelse med kursgjennomføringene.

\section{Stor interesse \\ for utdanning hos politiet}

Det viste seg å være stor interesse for førstehjelpstrening ute på politistasjonene. Oppmøtet på kursene var på 30-60\% av de ansatte ved de ulike stasjonene. Jeg anser dette å være et veldig høyt tall, tatt $\mathrm{i}$ betraktning at politiet arbeider i skift og har ansvar for en rekke vaktposter og patruljer rundt omkring i byen. Et halvt år etter oppstart av prosjektet hadde totalt 170 politimenn fra alle byens 11 politidistrikter fått frisket opp sine ferdigheter i førstehjelp (om lag $40 \%$ av politistyrken), og totalt 163 politimenn hadde fătt utlevert personlig førstehjelpsutstyr.

Kurset hadde deltakere fra alle de store etniske gruppene i Mazar-e Sharif, og både kvinner og menn var med. Vi hadde ingen problemer med å legge til rette for kvinnelige deltakere, til tross for at de afghanske kursinstruktørene alle var menn. Vi observerte imidlertid stor variasjon i førstehjelpskompetanse mellom de ulike politidistriktene i Mazar-e Sharif. Observasjonene muliggjør mer målrettet vektlegging av politihelse i tiden som kommer.

Våren 2014 støtter NOR PAT politiklinikken i Mazar-e Sharif i planleggingen av en kommende kursrunde i politidistriktene $\mathrm{i}$ byen og en utvidelse av prosjektet til å inkludere de øvrige politidistriktene i provinsen Balkh. Målet er at afghanerne selv skal gjennomføre denne kursrunden uten direkte deltakelse fra NOR PAT. På den måten ønsker vi å teste ut i hvilken grad initiativet nå kan stå på egne bein.

\section{Forsvaret $\mathrm{i}$ internasjonalt helsearbeid}

NOR PATs initiativ for politihelsearbeid er basert på en enkel modell og har, slik jeg ser det, potensial for bærekraft. I samarbeid med rådgiverteamet til sjefen for ISAF har jeg nå startet en prosess med tanke på å utarbeide anbefalinger for tilsvarende kurs i øvrige regioner av Afghanistan.

Vi har et håp om at vårt initiativ vil bidra til en mer robust politistyrke og økt stabilitet og utvikling for befolkningen i Afghanistan.

Jeg takker sykepleier/løytnant Arne, vognkommandør/fenrik Erik og vognfører/grenader Eirik for solid laginnsats gjennom seks måneder i Afghanistan og oberstløytnant Halvor Johansen, sjef NOR PAT høst 2013, for tett oppfølging og støtte av vårt politihelserådgivingsarbeid.

\section{Jon Magnus Haga (f. 1984)}

er stipendiat ved Nasjonalt kunnskapssenter om vold og traumatisk stress (NKVTS). Han har inntil nylig jobbet som lege i Forsvaret og utarbeidet høsten 2013 en strategi for sanitetsutvikling av afghansk politi gjennom Norwegian Police Advisory Team (NOR PAT). Han har fra tidligere erfaring fra internasjonalt helsearbeid gjennom studie- og forskningsopphold i flere land og som praktikant ved Verdens helseorganisasjon (WHO).

Forfatter har fylt ut ICMJE-skjemaet og oppgir ingen interessekonflikter.

\section{Litteratur}

1. Holcomb JB Stansbury LG, Champion HR et al. Understanding combat casualty care statistics. J Trauma 2006; 60: 397-401.

2. Haga JM. Tegn til bærekraft i afghansk anestesikompetanse. Tidsskr Nor Legeforen 2014; 134 : $1271-2$.

3. Husum H, Ang SC, Fosse E. War surgery. A field manual. Tromsø: Trauma Care Foundation, 2011.

4. Youtube. NATO. Norwegian Army train Afghan medics. www.youtube. . $0 \mathrm{~m} /$ watch? $v=5$ XqRSV9UPjg (11.4.2014).

Mottatt 29.11. 2013, første revisjon innsendt 24.2. 2014, godkjent 27.4. 2014. Redaktør: Siri Lunde Strømme. 